\title{
Determinants of Multidimensional Poverty among the Under-Five: Illustration Based on Data from the Congo Multiple Indicator Cluster Survey
}

\author{
Steve Bertrand Mboko Ibara1,2, Dukken Gaphi Ossouna² \\ ${ }^{1}$ Marien Ngouabi University, Brazzaville, Republic of Congo \\ ${ }^{2}$ National Institute of Statistics, Brazzaville, Republic of Congo \\ Email: stevemboko@yahoo.fr
}

How to cite this paper: Mboko Ibara, S. B., \& Ossouna, D. G. (2021). Determinants of Multidimensional Poverty among the Under-Five: Illustration Based on Data from the Congo Multiple Indicator Cluster Survey. Theoretical Economics Letters, 11, 363380

https://doi.org/10.4236/tel.2021.112024

Received: January 20, 2021

Accepted: April 22, 2021

Published: April 25, 2021

Copyright $\odot 2021$ by author(s) and Scientific Research Publishing Inc. This work is licensed under the Creative Commons Attribution International License (CC BY 4.0).

http://creativecommons.org/licenses/by/4.0/

\begin{abstract}
This research's objectives were to discuss the measurement of multidimensional poverty among children under five years of age and research the explanatory factors of this poverty. Using data from the Multiple Indicator Cluster Survey (MICS) carried out in 2015, a multidimensional poverty index for children under five years old was constructed using Alkire and Foster (2011). The private dimensions of children are early childhood education, health, and sanitation. Estimates carried out show that in 2015, multidimensional poverty affected 35 percent of children under five years old in Congo-Brazzaville. Also, the factors explaining this poverty include, among other things, the mothers' lack of education, place of residence, the household's standard of living, and the presence of several children in the same household. The results suggest the need to redress rural areas' disadvantages, particularly regarding access to basic social services.
\end{abstract}

\section{Keywords}

Multidimensional Poverty, Children under Five, Alkire and Foster Approach, Logit Model

\section{Introduction}

The United Nations (UN) adopted the Sustainable Development Goals (SDGs) in 2015 to improve the world population's living conditions over the next 15 years. Target 1.2 of the first goal is to reduce by at least half the proportions of 
men, women, and children of all ages living in poverty in all its dimensions, according to national definitions (UN, 2015). While poverty affects social groups (age or sex) differently, children feel its most devastating effects, for whom it poses a great threat by affecting their education, health, nutrition, and security (UNICEF, 2015) ${ }^{1}$.

Several reasons can be advanced for the importance of child-centered poverty (Boyden, 2006; Gordon et al., 2003). Indeed, a strong dependence on the direct environment for the distribution of basic needs exposes children to a higher risk of poverty and makes their situation less transparent (White et al., 2003). Because they are not independent economic actors on their own, they depend on the distribution of resources by their parents, members of their household, or their community. Also, children are not affected by poverty in the same way as adults are because children's basic human needs are different.

From a theoretical perspective, approaches to estimating child poverty have undergone several changes (Roelen and Gassmann, 2008). Ever since Roentree's (1901) pioneering work was published, both the theoretical and empirical debates on poverty are still relevant from an increasingly multidisciplinary perspective. Indeed, four measurement approaches have been developed to analyze child poverty: the monetary approach (Ravaillon, 2003), the Bristol deprivation approach (Gordon et al., 2003), the Alkire and Foster $(2007,2011)$ approach, and analysis of how multiple deprivations overlap (De Neubourg et al. 2012).

Poverty affects many children in the Republic of Congo. Indeed, 61 percent of the children in Congo (UNICEF, 2017) are in a situation of multidimensional poverty. Similarly, the study by Geranda et al. (2008) on the multidimensional poverty of children and women in Congo showed that poverty hits children more. In fact, the poverty rate found among children (54 percent) was higher than that among adults (46 percent). Severe malnutrition, which affects one in five adolescents, was also observed in 30.4 percent of children aged 0 - 71 months.

Like other African countries, Congo is part of a dynamic fight against poverty (Ouadika, 2018). The Congolese government has made the fight against poverty one of the major axes of its development strategy. This major concern has been manifested by adopting more than three decades of development plans focused on the fight against poverty. Because the deprivations that affect households can be expressed at the level of its members, one can wonder about the nature of the factors likely to explain this poverty among children under five years old. This research's main question is to determine the explanatory factors of multidimensional poverty among children under five years old in Congo. Although multidimensional poverty has already been the subject of several research studies performed in Congo (Geranda et al., 2008; Backiny, 2009; Mboko, 2015; Ambapour et al., 2016; UNICEF, 2017; Ouadika, 2018), these studies did not provide information on factors explaining the deprivation of children under five years old. Indeed, children are likely to exhibit vulnerabilities that can have lasting effects ${ }^{1}$ http://www.unicef.org/mdg/poverty.html. 
on their long-term development (Boyden and Bourdillon, 2012). The objectives are to discuss the measurement of multidimensional poverty among children under five years old and research the explanatory factors of this poverty. Specifically, these objectives involve 1) estimating the proportion of poor children and 2) analyzing the determinants of multidimensional poverty among children under five years old.

The remainder of the document is structured into three sections. Section 2 reviews the theoretical and conceptual aspects of measuring child poverty. Section 3 presents the methodological framework and the data used. Finally, the fourth section presents the main results on poverty among children under five years old.

\section{Literature Review}

\subsection{Theoretical Review}

Over the past decade, research on child poverty approaches has increased in both scope and depth, albeit limited. Approaches to child well-being and conceptualizing, defining, and measuring child deprivation have evolved (Roelen and Gassmann, 2008). Four main approaches to measuring child poverty have been developed: the monetary approach, the Bristol deprivation approach (Gordon et al., 2003), the Alkire and Foster $(2007,2011)$ approach, and the MODA approach (De Neubourg et al., 2012).

The monetary approach, which is the most commonly used measure of poverty, identifies the poor by setting a monetary poverty line based on the income needed to purchase a basket of basic goods and services. However, children are not economic agents and therefore cannot generate income for their own subsistence, making monetary indicators inadequate for capturing child poverty (White et al., 2003).

On the other hand, the Bristol approach derives a set of basic needs to which a child should have access and converts them into a series of deprivations when access to them is not available. These basic needs are food, clean water, sanitation, health care, shelter, education, and information. The measurement of child poverty in the Bristol approach is consistent with the capabilities approach. It's based on the child's rights and the definitions of poverty agreed upon at the international level at the 1995 World Summit for Social Development (Gordon et al., 2003). This approach improves monetary poverty, but it does not consider the magnitude, depth, or severity of dimensions of child poverty (Alkire et al., 2013). Besides, this approach does not allow for numbers to be broken down by dimension to discover child poverty components in the different groups (place of residence, age groups, or by sex).

The approach of Alkire and Foster (2007, 2011), revised by Alkire et al. (2019), assesses poverty by introducing two thresholds. The first is the deprivation threshold, which considers the dimensions retained in the poverty measurement and identifies individuals in deprivation in each of these dimensions. The second 
threshold defines a required minimum number of dimensions in which the individual is deprived for them to be counted among the poor. This approach uses Sen's (1979) capacity approach to construct the Global Multidimensional Poverty Index based on three dimensions: health, education, and standard of living (Alkire et al., 2015; Alkire and Santos, 2010). This allows the analysis of the magnitude, depth, or severity of child poverty dimensions and helps to break down information on child poverty across different groups. It measures poverty in two stages: 1$)$ an identification method ( $\rho k)$, in which "who is poor" is determined by considering the range of deprivations from which they suffer; 2 ) an aggregation method, in which an intuitive set of measures of poverty $(\mathrm{Ma})$ is generated (based on Foster-Greer-Thorbecke [FGT] measures), which can be decomposed to target the poorest people and the dimensions in which they are the most deprived. However, we cannot use this approach to assess the combinations of various deprivations from which children under five years of age suffer. Moreover, it takes a life-cycle approach that considers distinct age groups to reflect the differences in needs among infancy, childhood, and adolescence.

Finally, the MODA approach (De Neubourg et al., 2012) provides a comprehensive approach to the multidimensional aspects of poverty and (child) deprivation, takes the child as a unit of analysis, and emphasizes children's well-being by recognizing children's different needs at different stages of their lives. It adopts a holistic definition of child well-being, focusing on access to goods and services crucial for their survival and development. The dimensions of child well-being included in the MODA approach are categorized as reflecting three types of capital: physical capital (housing, sanitation, and water), human capital (nutrition, education, and health), and social capital (participation, information, and protection). Unlike Alkire's, this approach recognizes that children's needs are not homogeneous throughout their childhood. It takes a life-cycle approach that considers distinct age groups to reflect the differences in needs among infancy, childhood, and adolescence.

In sum, given the purpose of this research, we improve the approach of Alkire and Foster (2011) and measure poverty among children under five, using the child as the unit of analysis. The advantage of this approach over others is that it conveys new information that is not captured by any one-dimensional measurement on the common distribution and composition of child poverty.

\subsection{Empirical Review}

Several works have looked at quantifying multidimensional child poverty by considering certain dimensions of child survival. Roche (2009) used Alkire and Foster's approach to analyze child poverty in Bangladesh with data from the MICS 2006 survey. This work was carried out using eight dimensions of child wellbeing: clean water, improved sanitation, security of tenure and from eviction, measles vaccination, overcrowded housing, salt iodization, vitamin $\mathrm{A}$, and learn- 
ing support. The author's results showed that children were deprived of improved sanitation facilities and that this deprivation was more observed in rural than in urban areas. A similar result was obtained by Adetola and Olufemi (2012) on children under five years old in Nigeria by retaining five dimensions, namely water, sanitation, housing, health, and nutrition. These authors concluded that the health and sanitation dimensions contributed more to the multidimensional poverty of children under five years old than other factors did. Likewise, De Milliano and Plavgo (2018) retained six dimensions-health, nutrition, water, sanitation, housing, and domestic violence-to analyze multidimensional child poverty in sub-Saharan Africa. Using the MODA approach and DHS survey data, their results showed that 67 percent of children are multidimensionally poor in the 30 countries of sub-Saharan Africa. The dimensions of child deprivation they used were domestic violence (63.2 percent), sanitation (67.1 percent), and health (55.8 percent). In work on the multidimensional poverty of children under age five years in Congo using the MODA approach and six dimensions (child health, nutrition, protection of children, early childhood development, access to water. and housing), UNICEF (2017) showed that almost all children under five in the country are victims of at least one deprivation, with the main dimensions of deprivation among children under five concerning protection (75 percent), health (69 percent), and child development (63 percent). Roelen et al. (2010) used Alkire and Foster's identification approach to analyze poverty among children aged 0 to 15 years using 12 indicators divided into seven dimensions: education, health, housing, water and sanitation, child labor, leisure, and inclusion, and social protection. The results showed that over one-third (37 percent) of children live in poverty, with deprivation contributing most to multidimensional poverty being water, sanitation, and recreation.

Many studies deal with the explanatory factors of child poverty. Most of this work has focused on the household level, without considering the child as the analysis unit. Moreover, very few authors have published work on child poverty's explanatory factors related to the child and their household. Regarding child-related factors, the child's residence place is an important factor in explaining poverty among children under five years old (Adetola and Olufemi, 2012). Adetola and Olufemi (2012) show that children residing in rural areas in Nigeria are more exposed to multidimensional poverty. Likewise, Backiny (2009), Wasswa (2015), Ouadika (2018), and Ambapour (2020) used a logit model and concluded that living in rural areas increases the probability of remaining poor. A similar result was obtained by Mboko (2015) using a counting model. These results show that multidimensional child poverty is higher among children living in rural areas.

Regarding the children's age and sex, different studies on poverty do not reach the same conclusions. Rutaremwa (2013) and Francis Wasswa (2015) showed that gender influences child poverty. However, Adetola and Olufemi (2012) showed that a child's gender exerts no influence on child poverty. Concerning household 
variables, several works, such as those of Adetola and Olufemi (2012), Kabubo-Mariara et al. (2011), Ataguba et al. (2011), and Rutaremwa (2013), have shown, for example, that parents' education, household status, household size, and well-being quintile are determinants of poverty among children under five years old.

In short, the main results of this review reaffirm the multidimensional nature of child poverty. The dimensions of child deprivation differ depending on the context of the children's country. The few rare studies were just limited to the analysis of the multidimensional nature of child poverty. Admittedly, all of the work carried out in the Congo case has made it possible to explain child poverty without considering the determining factors of this poverty. All of this highlights the need to deepen the analysis of multidimensional child poverty and its explanatory factors.

\section{Importance and Originality of the Research}

When analyzing child poverty, the key questions include the correct identification of multidimensionally poor children and the extent of their poverty, second, how to design effective policies that will bring the greatest possible benefits. The first step in identifying poor children is choosing the dimensions that may affect children's survival, hence the importance of considering a wide range of dimensions specific to households and children. This research differs from the work of UNICEF (2017) and many others in two respects. The first is the inclusion of the two additional dimensions, namely domestic violence and access to electricity, for analyzing poverty among children under five years old. The second difference is the modification of Alkire and Foster's approach by taking the child as the unit of analysis and adding dimensions not considered by this approach.

\section{Methodology}

\subsection{Data Sources and Variables}

Data sources. As part of this research, the data came from the Congo Multiple Indicator Cluster Survey (MICS) conducted by the National Institute of Statistics (INS) of Congo between 2014 and 2015. This survey sample was a stratified, two-stage area sample with the first-stage stratification by place of residence. This sample comprised 9271 children aged 0 - 59 months at the time of the survey. The data from this survey are representative and provide information on individuals in households.

Study variables. The child-related variables used here are multidimensional child poverty status, child's age in months; child's sex; child's place of residence, number of children in the household, and the region in which the child lives. The variables linked to the child's household were the sex of the head of household, parental education, household size, wealth quintile of the head of household, and household employment status. 


\subsection{Method of Analysis}

The Alkire and Foster approach. The approach of Alkire and Foster (2007, 2011) has two stages: identification and aggregation. The first consists of introducing two thresholds. The first threshold is called the deprivation threshold, which is used to determine whether the child is deprived or not in a given dimension. The second poverty line, $k$, defines a required minimum number of dimensions in which the child is deprived of the poor. According to Alkire and Foster (2007), to identify multidimensionally poor children, we consider a poverty line such as $0<k \leq d$ (dimensions) and apply it to column vector $c$. Thus, a child is identified as poor if his or her weighted deprivations are $c \geq k$.

According to various criteria, deprivation in each dimension may be assigned equal or different weights, generally reflecting each dimension's normative importance to well-being. The aggregation step involves calculating three interrelated measures that reflect poverty in the entire population of interest. The first measure is the headcount ratio $(H)$ or incidence of poverty, which indicates the percentage of poor children, $H=q / n$. The second, called the intensity of deprivation among the poor $(A)$, indicates the poor's average deprivation $A=\frac{\sum_{i=1}^{n} c_{i}(k)}{d q}$ percentage. Finally, the adjusted headcount ratio $\left(M_{0}\right)$ is the ratio between the poor's deprivations and the total potential number of deprivations if the entire population was deprived in all dimensions. This adjusted ratio clearly satisfies dimensional monotonicity because it increases when a poor child is deprived of an additional dimension. An interesting property $M_{0}$ is that it can be decomposed into a subgroup of the population. This approach uses Sen's capacity approach as the conceptual framework for constructing the global multidimensional poverty index based on three dimensions: health, education, and standard of living (Alkire et al., 2015; Alkire and Foster, 2011; Alkire and Santos 2010).

\subsection{Dimensions, Deprivation Thresholds, and Weighting}

The multidimensional poverty index (MPI) is constructed based on a flexible methodology that can be easily adjusted to incorporate alternative indicators, thresholds, and weights that might be appropriate in different regional or national contexts (Alkire and Jahan, 2018). In general, the multidimensional poverty index is constructed based on the definitions of the indicators and the different thresholds and weights for each indicator. This research follows the weight structure of Gordon et al. (2003), who assigned equal weight to each dimension. The choice of dimensions and indicators follows, as far as possible, those of Gordon et al. (2003), UNICEF (2007), Roelen et al. (2012), and UNICEF (2017) (Table 1).

\subsection{Estimation Method}

In the research framework, the approach adopted to construct the multidimensional 
Table 1. Dimensions, weight, and thresholds of the MPI.

\begin{tabular}{|c|c|c|}
\hline Dimensions & Indicator/Deprivation thresholds & Weight \\
\hline Nutrition & $\begin{array}{l}\text { Children who are more than two standard deviations } \\
\text { below the international reference population for stunting } \\
\text { (height for age), wasting (weight for height), or } \\
\text { underweight (weight for age). Standardization follows } \\
\text { algorithms provided by the WHO Benchmark Child } \\
\text { Growth Study (WHO 2006). }\end{array}$ & $1 / 8$ \\
\hline Water & $\begin{array}{l}\text { Children who use water from an unimproved source, } \\
\text { such as an open well, an open-source, or surface water } \\
\text { (Unicef 2006) }\end{array}$ & $1 / 8$ \\
\hline Sanitation & $\begin{array}{l}\text { Children use unimproved sanitation facilities such as } \\
\text { slab fewer pit latrines, open pit latrines, bucket toilets, } \\
\text { and hanging toilets (WHO and UNICEF 2006). }\end{array}$ & $1 / 8$ \\
\hline Health & $\begin{array}{l}\text { A child over } 12 \text { months old has not received three DTP } \\
\text { vaccines, or the parents did not receive assistance from } \\
\text { an unqualified birth attendant during the child's birth. }\end{array}$ & $1 / 8$ \\
\hline Early Childhood Education & $\begin{array}{l}\text { A } 36 \text { - to } 59 \text {-month-old child not attending preschool } \\
\text { education or a child under } 3 \text { years old living in the same } \\
\text { household where a preschool-aged child ( } 36 \text { - } 59 \text { months) } \\
\text { is not enrolled in a preschool education program. }\end{array}$ & $1 / 8$ \\
\hline Electricity & $\begin{array}{l}\text { Children living in a household that does not have access } \\
\text { to electricity }\end{array}$ & $1 / 8$ \\
\hline Housing & $\begin{array}{l}\text { Children living in a house without a floor covering } \\
\text { (e.g., dirt or manure flooring) or with an inadequate roof } \\
\text { (e.g., thatch, palm leaf) }\end{array}$ & $1 / 8$ \\
\hline Violence & $\begin{array}{l}\text { The child lives in a household where a child aged } 2 \text { to } 14 \\
\text { is subjected to all types of physical abuse at the hands of } \\
\text { his or her parents }\end{array}$ & $1 / 8$ \\
\hline
\end{tabular}

child poverty index (MPI) is that of Alkire and Foster (2007, 2011), modified by considering the child as the unit of analysis. We adopt a logit model to analyze the probability of a child being poor from a multidimensional perspective. This model was chosen because the profile variable consists of a probability; thus, the independent variables' influences increase or decrease as the predicted probability approaches 0 or 1 (Long and Freese, 2006). The dependent variable is as follows:

$$
Y_{i}= \begin{cases}1 & \text { if the child is multidimensionally poor } \\ 0 & \text { if not }\end{cases}
$$

Subsequently, we can postulate a logit model with the following form:

$$
E\left(Y_{i} \mid X_{i}\right)=P\left(Y_{i}=1 \mid X_{i}\right)=\frac{1}{1+\mathrm{e}^{-x \beta / \sigma}}
$$

The parameter $\theta=\beta / \sigma$ is estimated using the maximum likelihood (MV) method. To interpret the model, the essential aspect to consider is the marginal effect given by the formula: 


$$
\frac{\partial P\left(Y_{i}=1\right)}{\partial x_{i j}}=\theta_{j} f\left(X_{i} \theta\right)
$$

\section{Presentation and Interpretation of the Results}

\subsection{Multidimensional Poverty Outcomes for Children under Five}

The results' presentation is preceded by choosing a poverty line to identify poor children from a multidimensional perspective. However, there is no specific procedure for determining this threshold. Alkire and Foster (2011) recommended calculating the indices for several threshold values and subsequently carrying out robustness checks to determine an optimal value for the threshold $\mathrm{k}$. For this analysis, we will consider the threshold of $\mathrm{k}=40$ percent to better identify poor children from a multidimensional perspective. The preliminary results show that 48.17 percent of children under five in Congo are multidimensionally poor. These poor children are deprived, on average, in 63.9 percent of the weighted poverty indicators analyzed. This leads to a value of 30.8 percent for the multidimensional poverty index for children under five years old.

Figure 1 shows the deprivation indicator values used to analyze the poverty index for children under five years old. Thus, children under five are confronted with more deprivation in the dimensions of early childhood education (50.2 percent), health (45.6 percent), sanitation ( 42.5 percent), electricity ( 38.5 percent), and housing ( 38 percent). These statistics provide the first basis for the policy's priorities to reduce multidimensional poverty among children under five years old.

These figures' demographic breakdown suggests large disparities for certain groups, which may also vary by indicator. Overall, there was no significant difference in figures between sexes in all child deprivation dimensions (see Figure 2). However, the breakdown by place of residence suggests a large urban-rural divide in Congo, particularly in the three deprivation domains.

\subsection{Decomposition of the Multidimensional Poverty Index}

One property of the MPI is that it can be broken down into subgroups or by

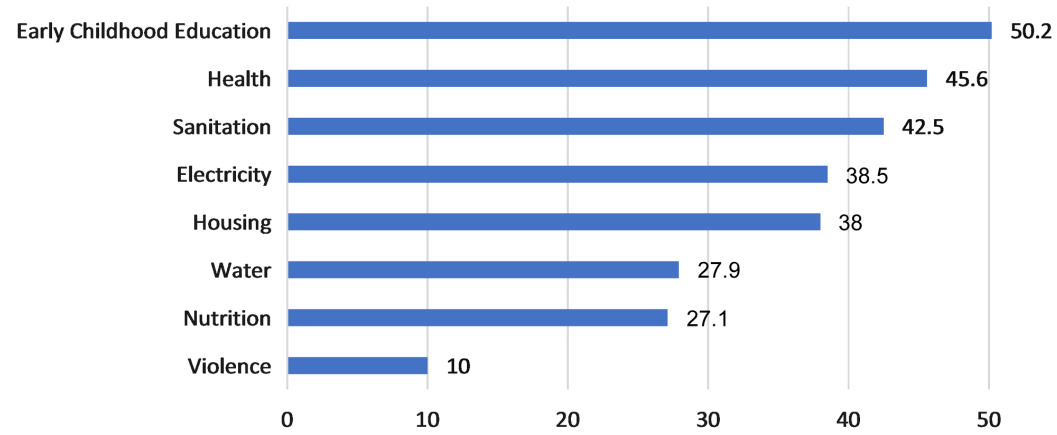

Figure 1. Proportions of poor and deprived children by dimension. Source: Authors, based on MICS2015 data. 

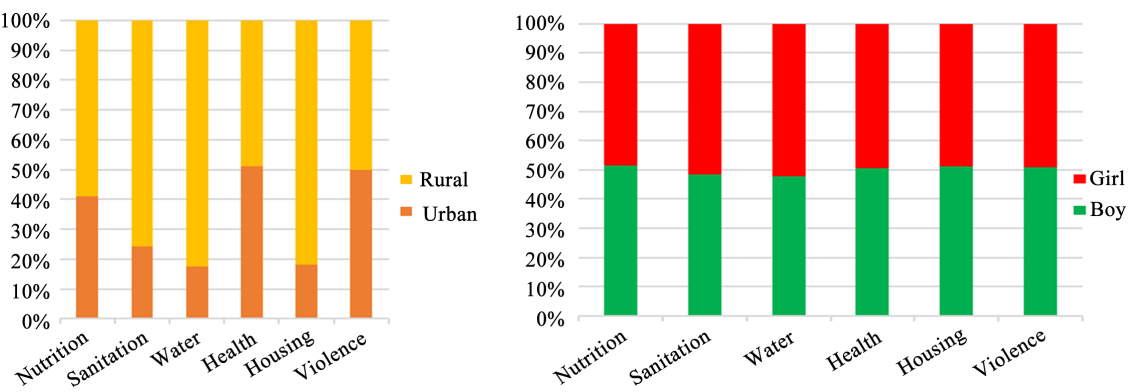

Figure 2. Deprivation rate by dimension according to children's place of residence and sex. Source: Authors, based on MICS2015 data.

dimension. Between 2014 and 2015, the multidimensional poverty rate $(\mathrm{H})$ for children under five years old was 52.2 percent, meaning that 52.2 percent of children were disadvantaged in at least four dimensions of the indicator. However, the $\mathrm{H}$ index's proportion does not provide exact information on the number of dimensions or indicators for which poor children are deprived of basic needs. This criticism is met by calculating the intensity (A), reflecting the average number of poor children's deprivations. Thus, 52.2 percent of children identified as multidimensionally poor are deprived, on average, in 67.02 percent of Congo's children's MPI indicators. The gender analysis shows that the difference between boys and girls is not significant. Regarding age groups, high poverty rates were observed for children in the age groups $0-11$ months and $12-47$ months. The depth of child poverty was significant for children aged $0-11$ months and decreased with age up to 35 months but increased again for children in the $36-47$ month and 48 - 59 month age groups.

Also, the incidence of multidimensional poverty among children under five years old is much higher in rural areas (89.98 percent) than in urban areas (29.53 percent), regardless of poverty used in one dimension. Also, the degree of deprivation of the indicators considered for poor children's population was more pronounced in rural areas (72.14 percent) than in urban areas (57.66 percent). As with the monetary approach, nonmonetary poverty affects rural areas much more than urban areas, as illustrated by Ambapour (2020) and Mboko (2015) on poverty in the Congo (Table 2).

The results by region also show considerable differences. Apart from Brazzaville (13.4 percent) and Pointe-Noire (21.8 percent), which had the lowest multidimensional poverty rates as compared to the national average (35 percent), the other departments are more affected by multidimensional poverty among children under five years old. Also, the departments of Cuvette-Ouest (72.3 percent), Pool (72.3 percent), Likouala (67.2 percent), Plateaux (66.9 percent), Sangha (59.6 percent), Lékoumou (63.2 percent), and Kouilou (62.6 percent) were most affected by multidimensional poverty among children under five. Departments with high multidimensional poverty also held the top rankings in terms of the incidence of poverty: the percentage of people who were both multidimensionally poor and the intensity of that deprivation. For example, children 
Table 2. Breakdown of multidimensional poverty indices according to group.

\begin{tabular}{cccc}
\hline Variables & H (\%) & A (\%) & MPI (\%) \\
\hline \multicolumn{2}{c}{ Boy } & Gender & \\
Girl & 51.91 & 67.16 & 34.86 \\
& 52.51 & 66.89 & 35.12 \\
$0-11$ & 58.97 & Age in months & \\
$12-23$ & 50.72 & 66.51 & 39.22 \\
$24-35$ & 53.94 & 66.32 & 33.64 \\
$36-47$ & 50.64 & 65.58 & 35.37 \\
$48-59$ & 46.90 & 68.13 & 34.50 \\
& \multicolumn{2}{c}{ Place of residence } & 32.24 \\
\hline Rural & 89.98 & 68.74 & 64.91 \\
Urban & 29.53 & 72.14 & 17.02 \\
National & 52.2 & 67.66 & 35.0 \\
\hline
\end{tabular}

Note: Authors' results based on MICS2015 data.

under five years of age most affected by multidimensional poverty in the department of Cuvette-Ouest experienced deprivation in 75.8 percent of the dimensions, on average (Table 3).

The contributions of each dimension to the multidimensional poverty of children under five show that the dimensions of early childhood education (17.9 percent), health (16.3 percent), sanitation (15.2 percent), electricity (13.8 percent), and housing (13.6 percent) had a strong contribution to the multidimensional poverty of children under age five in Congo (Figure 3 ).

The contributions of each dimension to the MPI training by place of residence show that the dimensions contributing to multidimensional poverty by place of residence were the same as those at the national level. Specifically, these were health, housing, and sanitation indicators. However, there are some differences between the two analyses in terms of the contribution of each dimension. Health contributes 15 percent to poverty in urban areas, against 20 percent in rural areas. On the other hand, the dimensions of sanitation, water, housing, and electricity have strong contributions to poverty in urban areas compared to rural areas (Figure 4).

\subsection{Explanatory Factors for Multidimensional Poverty among Children under Five}

The logit model's estimation results show that the model was globally significant at the 1-percent level. The results show that, of the nine variables introduced into the model, five presented statistically significant effects at a threshold less than or equal to 5 percent: age, area of the residence, well-being quintile, number of children in the household, and the mother's education. Therefore, we did not use the other insignificant variables in our interpretations (Table 4). 
Table 3. Breakdown of the multidimensional poverty indices of children under five by region.

\begin{tabular}{ccccc}
\hline Region & H (\%) & A (\%) & MPI & Mo (\%) \\
\hline Kouilou & 91.0 & 68.9 & .63 & 62.6 \\
Niari & 63.3 & 70.9 & .45 & 44.9 \\
Lekoumou & 85.8 & 73.7 & .63 & 63.2 \\
Bouenza & 73.1 & 67.9 & .50 & 49.6 \\
Pool & 97.2 & 74.4 & .72 & 72.3 \\
Plateaux & 92.5 & 72.3 & .67 & 66.9 \\
Cuvette & 78.2 & 65.3 & .51 & 51.1 \\
Cuvette-Ouest & 95.5 & 75.8 & .72 & 72.3 \\
Sangha & 82.8 & 72.0 & .60 & 59.6 \\
Likouala & 90.8 & 74.0 & .67 & 67.2 \\
Brazzaville & 23.9 & 56.1 & .13 & 13.4 \\
Pointe-Noire & 37.0 & 59.0 & .22 & 21.8 \\
National & 52.2 & 67.0 & .35 & 35.0 \\
\hline
\end{tabular}

Note: Authors' own results based on MICS2015 data.

Table 4. Odds-ratio results of the logistic regression model of poverty among children under five.

\begin{tabular}{|c|c|c|c|c|}
\hline Child poverty & Odds Ratio & Std. Err. & $\mathbf{z}$ & $p>\mathrm{z}$ \\
\hline \multicolumn{5}{|c|}{ Child's age (months) } \\
\hline $0-11$ & Ref. & Ref. & Ref. & Ref. \\
\hline $12-23$ & $.528^{\star * *}$ & .0622318 & -5.42 & .000 \\
\hline $24-35$ & $.479^{* * *}$ & .0555563 & -6.39 & .000 \\
\hline $36-47$ & $.470^{* \star *}$ & .0593605 & -5.84 & .000 \\
\hline $48-59$ & $.436^{* * *}$ & .0505815 & -7.15 & .000 \\
\hline \multicolumn{5}{|l|}{ Child's gender } \\
\hline Boy & Ref. & Ref. & Ref. & Ref. \\
\hline Girl & .916 & .0671345 & -1.20 & .230 \\
\hline \multicolumn{5}{|l|}{ Place of residence } \\
\hline Rural & Ref. & Ref. & Ref. & Ref. \\
\hline Urban & $.644^{* * *}$ & .052857 & -5.36 & .000 \\
\hline \multicolumn{5}{|l|}{ Wealth index } \\
\hline Poorest & Ref. & Ref. & Ref. & Ref. \\
\hline Second & $.0117^{* * *}$ & .0039715 & -13.10 & .000 \\
\hline Middle & $.00159^{* * *}$ & .0005501 & -18.64 & .000 \\
\hline Fourth & $.000584^{* * *}$ & .0002092 & -20.79 & .000 \\
\hline Richest & $.000224^{* * *}$ & .0000871 & -21.62 & .000 \\
\hline
\end{tabular}




\section{Continued}

\begin{tabular}{|c|c|c|c|c|}
\hline \multicolumn{5}{|l|}{ Household size } \\
\hline $1-4$ & Ref. & Ref. & Ref. & Ref. \\
\hline $5-6$ & .984 & .092053 & -.17 & .863 \\
\hline $7-8$ & 1.188 & .1314775 & 1.56 & .119 \\
\hline $9+$ & .919 & .1297977 & -.60 & .551 \\
\hline \multicolumn{5}{|c|}{ Gender of the household head } \\
\hline Male & Ref. & Ref. & Ref. & Ref. \\
\hline Female & 0,997 & .1222948 & -.02 & .980 \\
\hline \multicolumn{5}{|c|}{ Number of children in the household } \\
\hline 1 & Ref. & Ref. & Ref. & Ref. \\
\hline 2 & .984 & .0814359 & -.20 & .841 \\
\hline 3 & $1.294^{*}$ & .1758846 & 1.90 & .058 \\
\hline 4 & 1.196 & .2974239 & .72 & .471 \\
\hline \multicolumn{5}{|l|}{ Mother's education } \\
\hline No education & Ref. & Ref. & Ref. & Ref. \\
\hline Primary & .837 & .1444397 & -1.03 & .302 \\
\hline Secondary 1 & $.709^{* *}$ & .1174307 & -2.08 & .038 \\
\hline Secondary 2 or more & $.641^{* *}$ & .119272 & -2.39 & .017 \\
\hline \multicolumn{5}{|l|}{ Father's education } \\
\hline No education & Ref. & Ref. & Ref. & Ref. \\
\hline Primary & 1.133 & .2912539 & .49 & .627 \\
\hline Secondary 1 & .932 & .2244015 & -.29 & .771 \\
\hline Secondary 2 or more & .982 & .2410277 & -.08 & .940 \\
\hline _cons & $1.114^{\star \star \star}$ & 468.4271 & 16.68 & .000 \\
\hline
\end{tabular}

Source: Authors, based on MICS2015 data; ${ }^{* *} p<.01,{ }^{* *} p<.05,{ }^{*} p<.1$.

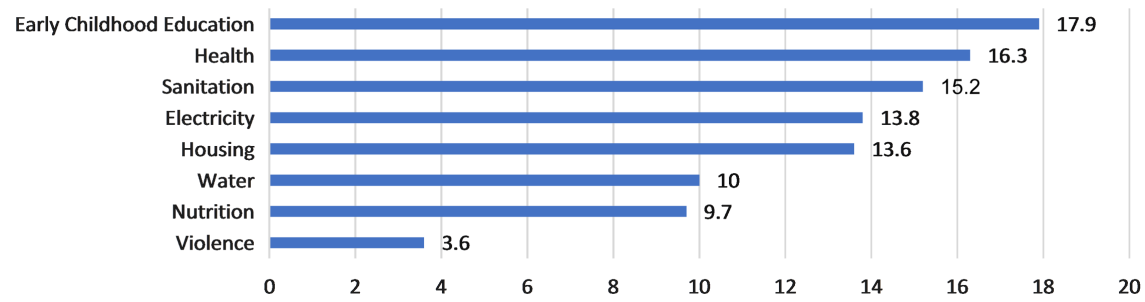

Figure 3. Contribution of each dimension to multidimensional poverty among children under five. Source: Authors, based on MICS2015 data.

Children's age shows that it is important to consider children's deprivations or needs when measuring poverty as the child grows. The coefficients for some age groups were large and significant at 1 percent. The age variable is negatively correlated with the likelihood of a child being poor. In other words, the older the child, the less likely the child will be poor than the reference modality. 

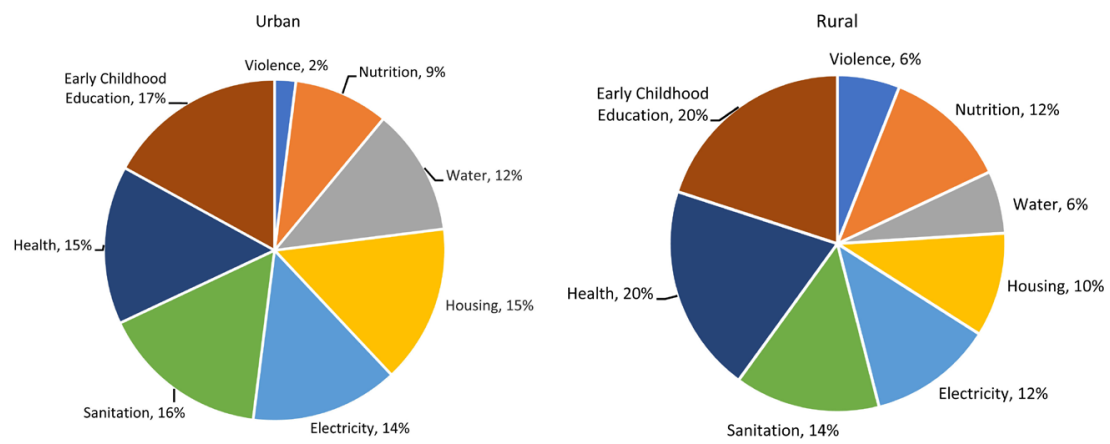

Figure 4. Contributions of the dimensions to child poverty in each place of residence. Source: Authors, based on MICS2015 data.

The results also show that the number of children under five in a household is a determinant of child poverty. Indeed, a child who lives in a household of three children has an increased probability of being poor than a child who lives in a household of one child. Having a child living in three children's household increases the risk of falling into poverty by 1.294 times compared to those living in a single-child household. Two explanations are possible. First, the specific consumption needs of young children are likely to weigh on household consumption habits. Second, having a larger number of children would divert work (especially women's time) from productive economic activities and lower-income and consumption (Kabubo et al., 2011).

A negative and significant effect was observed for children living in urban areas. Otherwise, children residing in rural areas were at greater risk of multidimensional poverty than those in urban areas were. The fact that a child lives in an urban area decreases their risk of falling into poverty by .644 times compared to a child living in a rural area.

A mother's education has a clear negative effect on the likelihood that a child will be multidimensionally poor. Children of mothers with secondary or higher education have much larger negative marginal effects, significant at the 1-percent level, indicating that the likelihood of a child being poor decreases with the child's mother's education level. However, based on the magnitude of the estimated marginal effects for different education levels, children living in households with less-educated mothers tend to be affected disproportionately by child poverty. This result agrees with Bastos and Machado (2009) conclusions, according to which education increases the stock of human capital.

Concerning the well-being quintile or wealth quintile, all of the different wealth categories' coefficients were significant at the 5-percent threshold. However, these modality variables are negatively correlated with the likelihood of a child being poor. This shows that as the household's wealth increases (from the "poorer" category to the next), a child's likelihood of being poor decreases. Children in households with a high wealth quintile are .000584 times less likely to be exposed to poverty than those in the poor class. The estimated marginal effect shows that .794 percentage points reduce the probability that a child from a "nonpoor" 
household will be multidimensionally poor.

Poor sanitary conditions, housing, and health undoubtedly negatively impact the poverty condition of children under five years old. Authors such as Adetola and Olufemi (2012) in Nigeria have shown that dimensions like health and sanitation contribute much to the multidimensional poverty of children under five years old. Likewise, UNICEF (2017) showed that child protection, health, and development are the dimensions that contribute the most to child poverty. Our results show that a child who lives in an urban environment, has an educated mother, lives in a nonpoor household, and lives in a household with fewer children under five will have a strongly reduced likelihood of being multidimensionally poor. These results corroborate those obtained by Adetola and Olufemi (2012), Kabubo-Mariara et al. (2011), Ataguba et al. (2011), Rutaremwa (2013), and Bastos and Machado (2009).

\section{Conclusion and Political Implications}

This research's objectives were to discuss how to measure multidimensional poverty among children under five and research the factors explaining this poverty in Congo. The discussion made it possible to retain Alkire and Foster (2011) approach and construct a multidimensional index of child poverty from eight dimensions. It appears that well-being dimensions such as early childhood education, health, and sanitation contribute most to this poverty. The factors from which child poverty originated were the mother's lack of schooling, several children in the household, a rural environment, and a household belonging to the poor class.

Research has finally shown that children's well-being depends not only on having access to a certain level of household income but also on access to adequate nutrition, better sanitation, good health, and good housing. This in turn means different policy responses in different areas, making the MPI useful for monitoring the effects of policy shifts and program changes (OPHI, 2020).

The results suggest the need to act quickly to redress rural areas' disadvantages, particularly regarding access to basic social services. They also suggest priority targeting of rural areas, particularly the necessity of public investment into sanitation, because even today, more than two in five children live in unimproved facilities. Finally, the results suggest the need to redouble efforts to expand quality primary health infrastructure to ensure access to children from more disadvantaged socio-economic strata, especially in rural areas.

Moreover, this research, like any other, has limits. Indeed, it did not include adolescents in the analysis of poverty. The study also failed to include children's views in the poverty measurement because adequate poverty measures must incorporate these views to ensure that they are socially realistic. Likewise, this research did not assess child poverty statistically. In this study, we did not consider certain variables such as household employment status that could be determining factors in child poverty. 
Thus, the extension of this work to analyze child possibility is possible through several research avenues. It would be important to explore, for example, the situation of certain population segments more exposed to deprivation, such as children aged 5 to 17 . Measuring poverty over a single period seems inadequate because it only gives a narrow picture of what poverty really is.

\section{Conflicts of Interest}

The authors declare no conflicts of interest regarding the publication of this paper.

\section{References}

Adetola, A., \& Olufemi, P. (2012). Determinants of Child Poverty in Rural Nigeria: A Multidimensional Approach. Global Journal of Human Social Science, 12, 1-17.

Alkire, S., \& Foster, J. (2007). Counting and Multidimensional Poverty Measurement. OPHI Working Paper 7, Oxford: Oxford University.

Alkire, S., \& Foster, J. (2011). Counting and Multidimensional Poverty Measurement. Journal of Public Economics, 95, 476-487. https://doi.org/10.1016/j.jpubeco.2010.11.006

Alkire, S., \& Foster, J. (2011). Understandings and Misunderstandings of Multidimensional Poverty Measurement. Journal of Economic Inequality, 9, 289-314. https://doi.org/10.1007/s10888-011-9181-4

Alkire, S., \& Jahan, S. (2018). The New Global MPI 2018: Aligning with the Sustainable Development Goals. OPHI Working Paper 121, Oxford: University of Oxford.

Alkire, S., \& Santos, M. E. (2010). Acute Multidimensional Poverty: A New Index for Developing Countries. OPHI Working Paper 38, Oxford: Oxford University. (Also Published as Human Development Research Paper 2010/11) https://doi.org/10.2139/ssrn.1815243

Alkire, S., Conconi, A., \& Roche, J. M. (2013). Multidimensional Poverty Index 2013: Brief Methodological Note and Results. OPHI MPI Methodological Note: MPI 2013.

Alkire, S., Foster, J., Seth, S., Santos, M. E., Roche, J. M., \& Ballon, P. (2015). Multidimensional Poverty Measurement and Analysis: A Counting Approach. Oxford: Oxford University Press. https://doi.org/10.1093/acprof:oso/9780199689491.001.0001

Alkire, S., Kanagaratnam, U., \& Suppa, N. (2019). Global Multidimensional Poverty Index 2019, OPHI MPI Methodological Notes 47. Oxford Poverty and Human Development Initiative, Oxford: University of Oxford.

Ambapour, S. (2020). Using Multiple Correspondence Analysis to Measure Multidimensional Poverty in Congo. Journal of Data Analysis and Information Processing, 8, 241266. https://doi.org/10.4236/jdaip.2020.84014

Ambapour, S., Okandza, J. C., \& Moussana, H. (2016). Multidimensional Poverty and Fertility in Congo. Open Journal of Social Sciences, 4, 137-149. https://doi.org/10.4236/jss.2016.43020

Ataguba, J., Fonta, W. M., \& Ichoku, H. E. (2011). The Determinants of Multidimensional Poverty in Nsukka, Nigeria. PMMA Working Paper 13, Poverty and Economic Policy Research Network (PEP). https://doi.org/10.2139/ssrn.1937721

Backiny, P. (2009). Profil et perceptions de la pauvreté en République du Congo en 2005. http://www.perspaf.org/ 
Bastos, A., Casaca, S., Nunes, F., \& Pereirinha, J. (2009). Women and Poverty: A Gender-Sensitive Approach. The Journal of Socio-Economics, 38, 764-778.

https://doi.org/10.1016/j.socec.2009.03.008

Boyden, J. (2006). Young Lives Project. Concepts and Analytical Framework. Oxford: Young Lives.

Boyden, J., \& Bourdillon, M. (Eds.) (2012). Childhood Poverty. Multidisciplinary Approaches. Basingstoke: Palgrave. https://doi.org/10.1057/9780230362796

De Milliano, M., \& Plavgo, I. (2018). Analysing Multidimensional Child Poverty in SubSaharan Africa: Findings Using an International Comparative Approach. Child Indicators Research, 11, 805-833. https://doi.org/10.1007/s12187-017-9488-1

De Neubourg, C., Chai, J., de Milliano, M., Plavgo, I., \& Wei, Z. (2012). Step-by-Step Guidelines to the Multiple Overlapping Deprivation Analysis (MODA). Working Paper 2012-10, Florence: UNICEF Office of Research.

Geranda, N., Makosso, B., \& Mpoue, A. B. (2008). Pauvreté multidimensionnelle des enfants et des femmes en République du Congo. Brazzaville: Rapport d'analyse, Unicef.

Gordon, D., Nandy, S., Pantazis, C., Pemberton, S., \& Townsend, P. (2003). Child Poverty in the Developing World. Bristol: The Policy Press.

Kabubo-Mariara, J., Wambugu, A., \& Musau, S. (2011). Multidimensional Poverty in Kenya: Analysis of Maternal and Child Wellbeing. Working Papers PMMA, PEPPMMA. https://doi.org/10.2139/ssrn.1935594

Long, J.-S., \& Freese, J. (2006). Regression Models for Categorical Dependent Variables Using Stata. College Station, TX: Stata Press.

Mboko I., S. B. (2015). Pauvreté des ménages et éducation au Congo: Application d'un modèle de comptage à partir des données du RGPH 2007. Québec: Observatoire démographique et statistique de l'espace francophone/Université Laval, 56 p. (Collection Rapport de recherche de l'ODSEF)

OPHI (2020). Global MPI Country Briefing 2020: Congo (Sub-Saharan Africa). Oxford: University of Oxford, 1-11.

http://www.ophi.org.uk/wp-content/uploads/CB COG 2020.pdf

Ouadika, S. (2018). Analyse de la dynamique de pauvreté au Congo. Thèse de Doctorat, Brazzaville: Université Marien Ngouabi.

Ravallion, M. (2003). The Debate on Globalization, Poverty and Inequality: Why Measurement Matters. Washington, DC: Development Research Group, World Bank. https://doi.org/10.1596/1813-9450-3038

Roche, J.-M. (2009). Child Poverty Measurement: Assessment of Methods and an Application to Bangladesh. Social Indicators Research.

Roelen, K., \& Gassman, F. (2008). Measuring Child Poverty and Well-Being: A Literature Review. MPRA Paper, Munich: University Library of Munich. https://doi.org/10.2139/ssrn.1105652

Roelen, K., Gassman, F., \& de Neubourg, C. (2010). Child Poverty in Vietnam: Providing Insights Using a Country Specific and Multidimensional Model. Social Indicators Research, 98, 129-145. https://doi.org/10.1007/s11205-009-9522-x

Roelen, K., Gassmann, F., \& de Neubourg, C. (2012). False Positives or Hidden Dimensions-What Can Monetary and Multidimensional Measurement Tell Us about Child Poverty? Journal for International Social Welfare, 21, 393-407.

https://doi.org/10.1111/j.1468-2397.2011.00836.x

Roentree, S. (1901). Poverty: A Study of Town Life. London: Macmillan. 
Rutaremwa, G. (2013). Child Poverty in Uganda: Analysis of the UNHS 2009/2010 Survey. American Journal of Sociological Research, 3, 36-45.

Sen, A. (1979). Utilitarianism and Welfarism. Journal of Philosophy, 76, 463-489. https://doi.org/10.2307/2025934

UNICEF (2007). Global Study on Child Poverty and Disparities 2007-2008 Guide. New York: Global Policy Section Division of Policy and Planning.

UNICEF (2015). Millennium Development Goals. http://www.unicef.org/mdg/poverty.html

United Nations (UN) (2015). Transforming Our World: The 2030 Agenda for Sustainable Development.

Wasswa, F. (2015). Multidimensional Child Poverty and Its Determinants: A Case of Uganda. Ph.D. Dissertation in Economics, Canberra: University of Canberra.

White, H., Leavy, J., \& Masters, A. (2003). Comparative Perspectives on Child Poverty: A Review of Poverty Measures. Journal of Human Development, 4, 379-396.

https://doi.org/10.1080/1464988032000125755 